Research Article

\title{
Microstructure Characteristics and Corrosion Resistance of Friction Stir Welded 2205 Duplex Stainless Steel
}

\author{
Yunqiang Zhao $\mathbb{D}$, Chunlin Dong $\mathbb{D}$, Zhongxue Jia $\mathbb{D}^{D}$, Jiaqing You $\mathbb{D}$, Jinhong Tan $(\mathbb{D}$, \\ Shu Miao $(\mathbb{D}$, and Yaoyong Yi 1
}

Guangdong Provincial Key Laboratory of Advanced Welding Technology, China-Ukraine Institute of Welding, Guangdong Academy of Sciences, Guangzhou 510650, China

Correspondence should be addressed to Yunqiang Zhao; zhaoyq@gwi.gd.cn and Shu Miao; miaosh@gwi.gd.cn

Received 4 September 2020; Revised 29 January 2021; Accepted 4 February 2021; Published 23 February 2021

Academic Editor: Jörg M. K. Wiezorek

Copyright (C) 2021 Yunqiang Zhao et al. This is an open access article distributed under the Creative Commons Attribution License, which permits unrestricted use, distribution, and reproduction in any medium, provided the original work is properly cited.

In this study, 2205 duplex stainless steel was friction-stir-welded at different welding speeds. The microstructural characteristics such as grain sizes, grain boundary misorientation angles, and phase contents in the stir zones of the joints were detected. The potentiodynamic polarization and electrochemical impedance spectroscopy were also measured to evaluate the corrosion property of the stir zones. The effects of the microstructures on the corrosion property for friction-stir-welded 2205 duplex stainless steel were analyzed. The results indicated that the FSW process refined the grains and increased the ferrite contents in the stir zones. With increasing the welding speed from $30 \mathrm{~mm} / \mathrm{min}$ to $50 \mathrm{~mm} / \mathrm{min}$, the grain size in the stir zone decreased from $1.64 \mu \mathrm{m}$ to $0.96 \mu \mathrm{m}$, the ferrite content decreased from $59 \%$ to $54.4 \%$, and the fractions of low angle grain boundaries for austenite and ferrite phases decreased from $63.9 \%$ and $92.6 \%$ to $18.0 \%$ and $41.1 \%$, respectively. In this study, the effect of grain size on the corrosion resistance was the most significant and it was followed by the phase composition and the grain boundary misorientation angle. The stir zone obtained at $50 \mathrm{~mm} / \mathrm{min}$ has the highest corrosion resistance, and it is followed by the base material and the stir zone obtained at $30 \mathrm{~mm} / \mathrm{min}$.

\section{Introduction}

Duplex stainless steel (DSS) whose microstructure consists of appropriately balanced ferrite $(\alpha)$ and austenite $(\gamma)$ phases has been widely applied owing to its high mechanical and corrosion properties [1]. However, the corrosion resistance of DSS will be dramatically reduced when the DSS experiences conventional fusion welding. This is because the balanced phase composition will be disequilibrated and detrimental sigma $(\sigma)$ phase will precipitate. Friction stir welding (FSW) is a solid-state welding technology [2]. In this welding process, the welded metal is not melted; as a result, the balanced phase composition can be maintained and the precipitation of sigma phase can be restrained [3]. Therefore, FSW is a promising technology to overcome the problems caused by the fusion welding methods.
Some studies on FSW of DSS have been carried out and they were mainly related to welding process, joint microstructure, and mechanical properties $[4,5]$. For example, Wang et al. [6] studied the effect of the tool rotation speed on the microstructures and mechanical properties of the FSW joint of 2205 DSS. They found that defect-free welds can be obtained when the welding speed was fixed at $1000 \mathrm{~mm} / \mathrm{min}$ and the rotational speed varied in the range of 300-500 rpm. With the increase of tool rotational speed, the welding heat input increased and the joint strength decreased. Abubaker et al. [7] used friction stir processing to improve the microstructure and mechanical properties of 2207 DSS. The results indicated that grains were refined from a size of $160 \mu \mathrm{m}$ to $2 \sim 30 \mu \mathrm{m}$ in the processed zone and the strength, hardness, and fracture toughness of the material were increased by $14 \%, 11 \%$, and $12 \%$, respectively. Emami et al. [8] pointed out that the grain refinement mechanism in the stir 
zone was continuous dynamic recrystallization caused by increasing the misorientation angle of substructures formed during the dynamic recovery. Saeid et al. [9] also found that, in the FSW of 2205 DSS, the ferrite was subject to continuous dynamic recrystallization (CDRX), while the austenite experienced both static recrystallization (SRX) and CDRX. Because the phase transformation of DSS will significantly affect the material mechanical and corrosion properties, some studies on the phase composition of FSW joint were carried out. Saeid et al. [10] studied the microstructure of 2205 DSS FSW joint. The results indicated that the ratio of $\alpha / \gamma$ in the stir zone (SZ) was roughly the same as the base material (BM), since the peak temperatures of weld thermal cycles were lower than the temperature of $\gamma$ to $\alpha$ transformation. Sugimoto et al. [11] studied the precipitation behavior in the FSW joint of UNS-S32750 DSS. They opined that the $\sigma$ phase precipitated in the heat-affected zone and the $\mathrm{Cr}_{2} \mathrm{~N}$ and the $\chi$ phase precipitated in the stir zone of the joint. Since the DSS usually services in corrosive environment, the corrosion resistance of the DSS FSW joint should be paid more attention. Sarlak et al. [12] studied the corrosion behavior of friction-stir-welded lean duplex stainless steel. They found that the stir zones (SZ) at all the welding parameters exhibited superior corrosion resistance than the $\mathrm{BM}$. The authors also pointed out that the corrosion resistance of the DSS FSW joint is mainly determined by the rate of $\alpha / \gamma$ and the grain size. A similar result was also found in the study on FSW of 2707 DSS conducted by Li et al. [13].

Although the corrosion properties of the DSS FSW joint deserve attention, the reported studies on this are still insufficient. The effect of microstructure on corrosion resistance of DSS FSW joint in particular needs to be further investigated. Therefore, in this study, 2205 DSS was frictionstir-welded and the microstructure characteristics and corrosion resistance of the SZs were studied. Particular attention was paid to the relationship between microstructure and corrosion resistance of the SZs.

\section{Materials and Methods}

2205 DSS plates with $4 \mathrm{~mm}$ thickness were used as the base material, the chemical compositions of which are listed in Table 1 . The plates were machined into rectangular welding samples with dimension of $300 \mathrm{~mm}$ length by $100 \mathrm{~mm}$ width. A W-Re alloy tool with $16 \mathrm{~mm}$ shoulder diameter and $3.9 \mathrm{~mm}$ pin length was employed. The pin of the welding tool was circular cone with a cone angle of 20 degrees, and the diameter of the pin root was $6.8 \mathrm{~mm}$. The shape and dimension of the welding tool are shown in Figure 1. The welding experiments were carried out on the FSW-D-3020$10 \mathrm{~T}-2 \mathrm{D}$ welding machine produced by China-Ukraine Institute of Welding, Guangdong Academy of Sciences. For the FSW experiments, the tool rotation speed was fixed at $600 \mathrm{rpm}$. Different welding speeds $(30 \mathrm{~mm} / \mathrm{min}$ and $50 \mathrm{~mm} /$ $\mathrm{min})$ were employed in order to establish the relationship among the welding speed, the microstructure, and the corrosion resistance of the joints. For convenience, the SZs of the joints obtained at the welding speeds of 30 and $50 \mathrm{~mm} /$ min are denoted as SZ-30 and SZ-50, respectively.
TABle 1: Chemical compositions of 2205 DSS.

\begin{tabular}{lcccccccc}
\hline \multicolumn{10}{c}{ Chemical compositions, wt.\% } \\
\hline $\mathrm{C}$ & $\mathrm{Si}$ & $\mathrm{Mn}$ & $\mathrm{Ni}$ & $\mathrm{Cr}$ & $\mathrm{N}$ & $\mathrm{P}$ & $\mathrm{Mo}$ & $\mathrm{Fe}$ \\
\hline 0.02 & 0.57 & 1.25 & 5.30 & 22.57 & 0.14 & 0.03 & 3.04 & Bal. \\
\hline
\end{tabular}

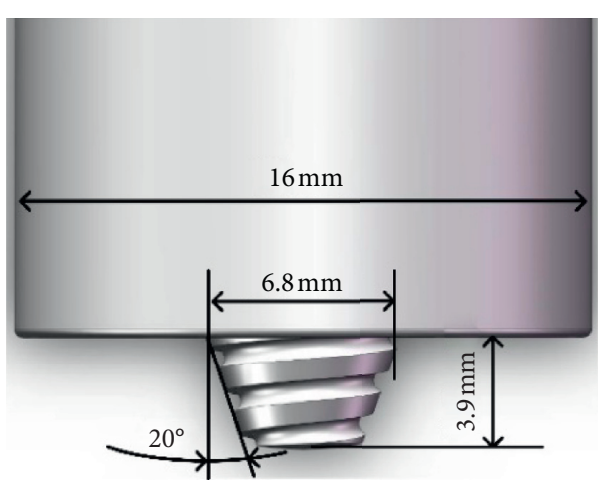

FIgURE 1: Schematic of welding tool.

A SmartLab X-ray diffractometer was employed to identify the phases in the SZ of the joint. The ferrite content in the SZ was measured by a ferrite measuring instrument (FERITSCOPE FMP30) according to the magnetic induction method. The ferrite content was determined by averaging the results of five points along the SZ center line in the cross section of the joint. The distance from the top point to the upper surface of the joint was $0.5 \mathrm{~mm}$, and the distance between the adjacent points was $1 \mathrm{~mm}$. The microstructure analyses were conducted on the cross section of the FSW joint by electron backscattering diffraction (EBSD) using Zeiss-Merlin scanning electron microscope (SEM). Before the EBSD testing, the specimens were sanded and mechanically polished, and then they were ion-beampolished for 1 hour on the Leica EM TIC 3X ion beam milling system.

Potentiodynamic polarization and electrochemical impedance spectroscopy (EIS) were measured using a PARSTAT 4000 electrochemical workstation. Before testing, the SZ specimens with an area of $3 \mathrm{~mm} \times 3 \mathrm{~mm}$ were cut from the FSW joint using an electrical discharge cutting machine. After that, the specimens were successively cleaned by acetone, sanded, and polished. The potentiodynamic polarization measurements were carried out using a threeelectrode electrochemical cell system in 3.5 wt. $\% \mathrm{NaCl}$ water solution. The working electrode, the reference electrode, and the auxiliary electrode were SZ specimen, saturated calomel electrode (SCE), and Pt plate, respectively. The potential was scanned from $-1 \mathrm{~V}$ to $1.5 \mathrm{~V}$ versus the open circuit potential (OCP) with a scan rate of $1 \mathrm{mV} / \mathrm{s}$. The measuring frequency range for the EIS was from $10^{4}$ to $10^{-2} \mathrm{~Hz}$. The alternating current (AC) excitation signal amplitude was $\pm 5 \mathrm{mV}$. After testing, the measured EIS data were analyzed according to an equivalent circuit by the ZView software. The specimen after the electrochemical measurements was analyzed by the SEM. After the electrochemical tests, the surfaces of the specimens were observed using SEM (FEI Quanta 250), and the 
elements distributions near the corrosion pits were measured by energy dispersive spectroscopy (EDS).

\section{Results and Discussion}

3.1. Microstructural Characteristics. Figure 2 shows the cross sections of FSW joints obtained at different welding speeds. The stir zone (SZ) is in the middle of the joint, the shape of which is bowl. In this zone, the material is stirred directly by the welding tool in the FSW process; as a result, the material in SZ experiences severe welding thermal cycle and plastic deformation. It can be seen that, with increasing the welding speed, the size of the SZ is decreased. This can be attributed to less stir effect at higher welding speed. For a FSW joint, the area of SZ is the largest, so that the corrosion property of this zone has significant effect on the corrosion resistance of the whole joint. Next to SZ is the thermomechanically affected zone (TMAZ), which is subjected to the shear force of SZ plastic metal and thermal effect at the same time. The heataffected zone (HAZ) is further away from the center of the weld, and this area is only affected by heat until it extends to the base metal (BM).

Figure 3 shows the grain morphologies demonstrated by EBSD in the SZs at different welding speeds. For comparison purposes, a typical EBSD image of the BM is also illustrated. It can be observed that the grains in the BM are elongated along the rolling direction, and the average length of the grains is $5.6 \mu \mathrm{m}$ (see Figure 3(a)). When the welding speed is $30 \mathrm{~mm} / \mathrm{min}$, the grains in the SZ are fine and equiaxed with an average diameter of $1.64 \mu \mathrm{m}$ (see Figure 3(b)). It is well accepted that the fine and equiaxed grains in the SZ are caused by dynamic recrystallization under the effects of severe welding thermal cycle and plastic deformation during FSW $[14,15]$. The dynamic recrystallization mechanism for a given material is usually dependent on the strain and strain rate histories, as well as the stacking fault energy (SFE) of the material [16]. It can be believed that both the austenite and ferrite experienced similar strain and strain rate histories in the SZ, which is a relatively small space. As a result, the dynamic recrystallization mechanisms of the different phases are mainly determined by their SFE. Saeid et al. [10] pointed out that the austenite whose SFE is relatively low generally undergoes discontinuous dynamic recrystallization, since the dislocations tend to dissociate, making recovery more difficult. Meanwhile the ferrite that has high SFE tends to undergo continuous dynamic recrystallization. It should be noted that when the welding speed is increased to $50 \mathrm{~mm} / \mathrm{min}$, the average diameter of the grains in the SZ decreases to $0.96 \mu \mathrm{m}$ (see Figure 3(c)). This can be attributed to the lower welding heat input at the relatively high welding speed.

A lot of dislocations are induced by the large plastic deformation during FSW. This leads to the formation of low angle grain boundaries (LABs) with misorientation angles between 2 and 15 degrees $[4,14,17]$. In general, the LABs have effect on the corrosion resistance of the material [18]. Figure 4 shows the statistics of grain boundary misorientation angle distributions of BM and SZs at different welding speeds. For the austenite, the effect of the FSW process on the fraction of the LABs $\left(f_{\mathrm{LAB}}\right)$ is not consistent. The values of $f_{\mathrm{LAB}}$ for BM, SZ-30, and SZ-50 are $36.1 \%, 63.9 \%$, and $18.0 \%$, respectively. Meanwhile, for the ferrite, the FSW process can obviously increase $f_{\mathrm{LAB}}$. Compared with the $\mathrm{BM}$, the value of $f_{\mathrm{LAB}}$ is increased from $35.7 \%$ to $92.6 \%$ and $41.1 \%$ when the welding speeds are $30 \mathrm{~mm} / \mathrm{min}$ and $50 \mathrm{~mm} / \mathrm{min}$, respectively. This difference of the effects of the FSW process on the austenite and ferrite can be attributed to the different recrystallization mechanisms of these two phases. In addition, for both austenite and ferrite, $f_{\mathrm{LAB}}$ is decreased with increasing the welding speed. The reason for this is that lower welding speed can induce more dislocations under the larger plastic deformation, and then the LABs are increased.

For the DSS, phase compositions have significant influence on its corrosion resistance. As shown in Figure 5(a), only the ferrite and the austenite phases can be identified by XRD patterns for all the welding conditions. It should be pointed that the sigma $(\sigma)$ phase, which has significant adverse effect on the corrosion resistance of DSS [19, 20], cannot be detected. This indicates that the sigma phase is not precipitated in the SZ or its amount was lower than $5 \%$. The formation mechanism of the $\sigma$ phase is a eutectoid transformation of ferrite into austenite and sigma phase $\left(\alpha \longrightarrow \gamma_{3}+\sigma\right)$ with the temperature decreasing from 1000 to $600^{\circ} \mathrm{C}[21]$. For the fusion welding, the $\sigma$ phase is usually detected in the joint because of the relatively high temperature and low cooling rate [20]. In contrast, the $\sigma$ phase formation can be restrained by FSW, because the FSW process of DSS exhibits much lower peak temperature and higher cooling rate than these of fusion welding.

As shown in Figure 5(b), compared with the BM, the ferrite contents of the SZs are increased by FSW. According to the $\mathrm{Fe}-\mathrm{Cr}-\mathrm{Ni}$ three-component alloy phase diagram shown in Figure 5(c), it can be concluded that the transformation from austenite into ferrite occurs when the temperature is increased in FSW. After welding, the formed ferrite is retained at high cooling rate. That is to say, the increase of the ferrite content in the SZ can be attributed to the welding thermal cycle and the ferrite increment is dependent on the peak temperature. For the FSW, both tool rotational speed $(\omega)$ and welding speed $(v)$ exert a significant effect on the peak temperature $[4,22]$. It has been demonstrated that the peak temperature $\left(T_{p}\right)$ in FSW can be expressed as a function of the pseudo-heat-index $\left(\omega^{2} / v\right)$ as follows [23]:

$$
\frac{T_{p}}{T_{m}}=K\left(\frac{\omega^{2}}{v^{4}}\right)^{\alpha}
$$

where $K$ and $\alpha$ are constants and $T_{m}\left({ }^{\circ} \mathrm{C}\right)$ is the melting point of the DSS. It can be concluded that when the tool rotation speed is constant, higher peak temperature can be achieved when the welding speed is lower. In addition, according to the studies conducted by Saeid et al. [10] and Santos et al. [24], the peak temperature in FSW of 2205 DSS is lower than $1300^{\circ} \mathrm{C}$, above which the austenite fully transforms into ferrite. As a result, the ferrite content in the SZ increases from $54 \%$ to $59 \%$ when the welding speed decreases from 50 to $30 \mathrm{~mm} / \mathrm{min}$. 

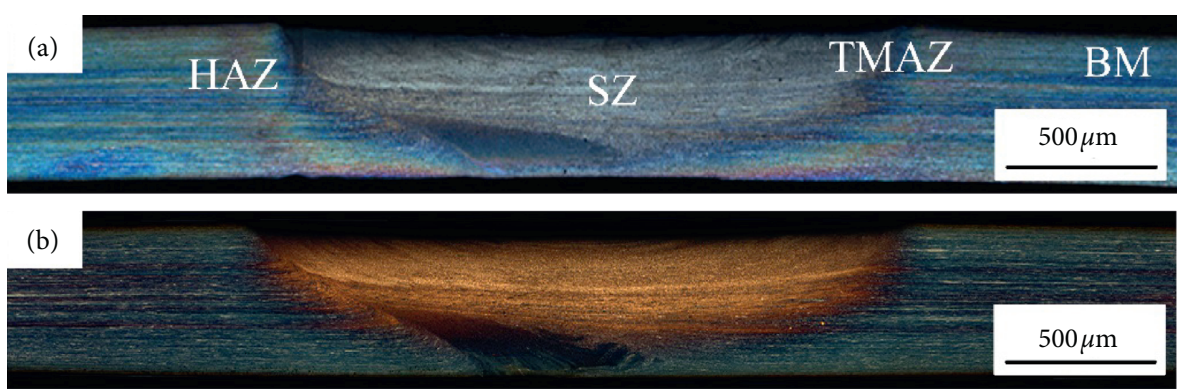

Figure 2: Cross sections of joints obtained at different welding speeds: (a) $30 \mathrm{~mm} / \mathrm{min}$ and (b) $50 \mathrm{~mm} / \mathrm{min}$.
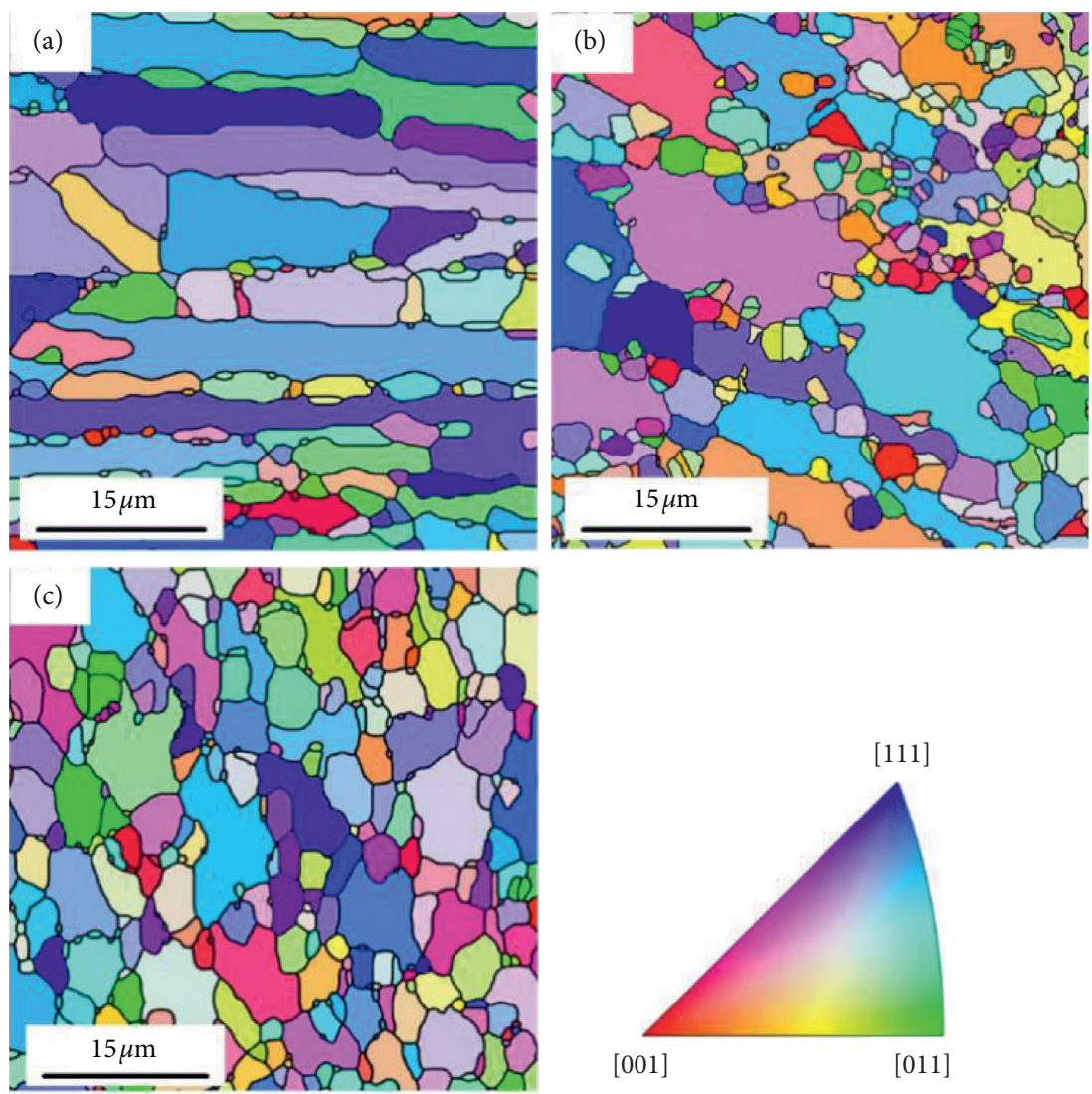

Figure 3: Grain morphologies in (a) base material, (b) stir zone obtained at $30 \mathrm{~mm} / \mathrm{min}$, and (c) stir zone obtained at $50 \mathrm{~mm} / \mathrm{min}$.

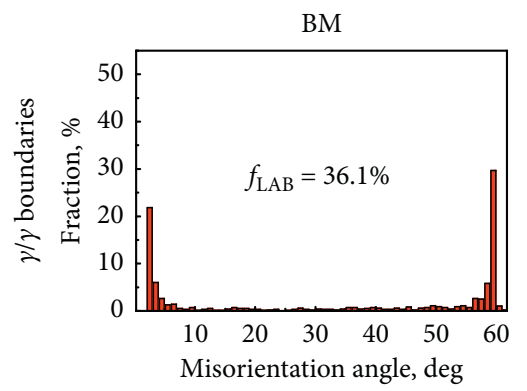

(a)

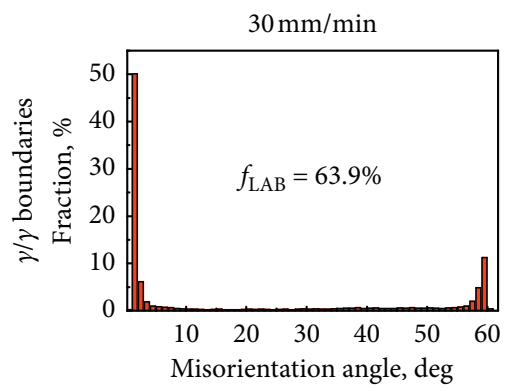

(b)

FIgURE 4: Continued. 


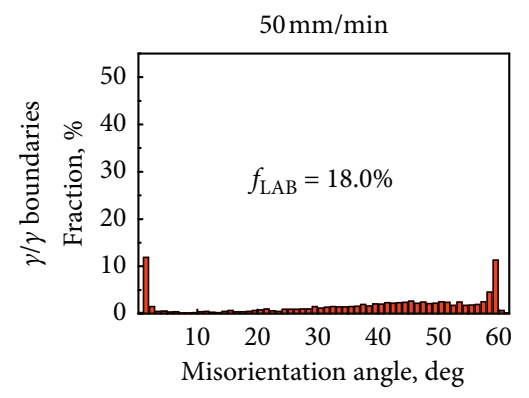

(c)

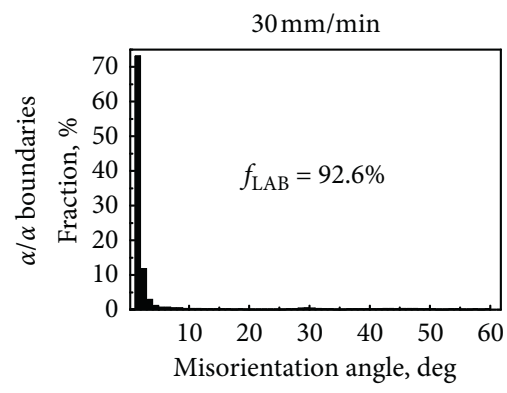

(e)

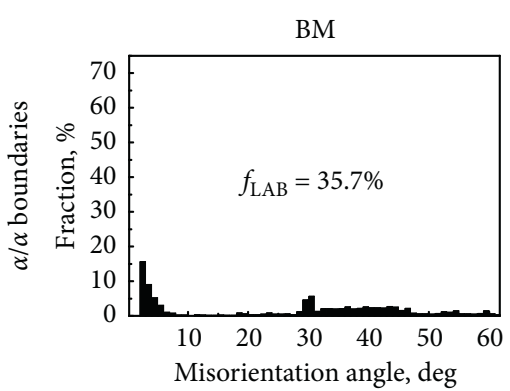

(d)

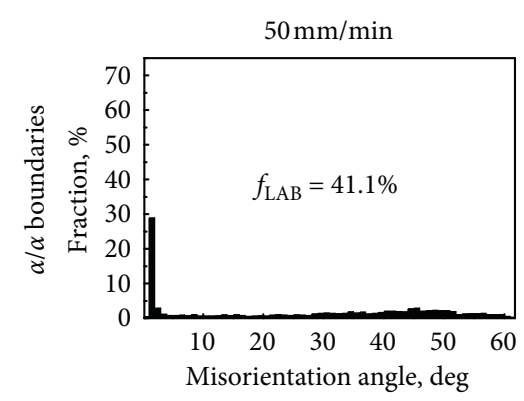

(f)

FIGURE 4: Statistics of grain boundary misorientation angle distributions of base material and stir zones at different welding speeds.

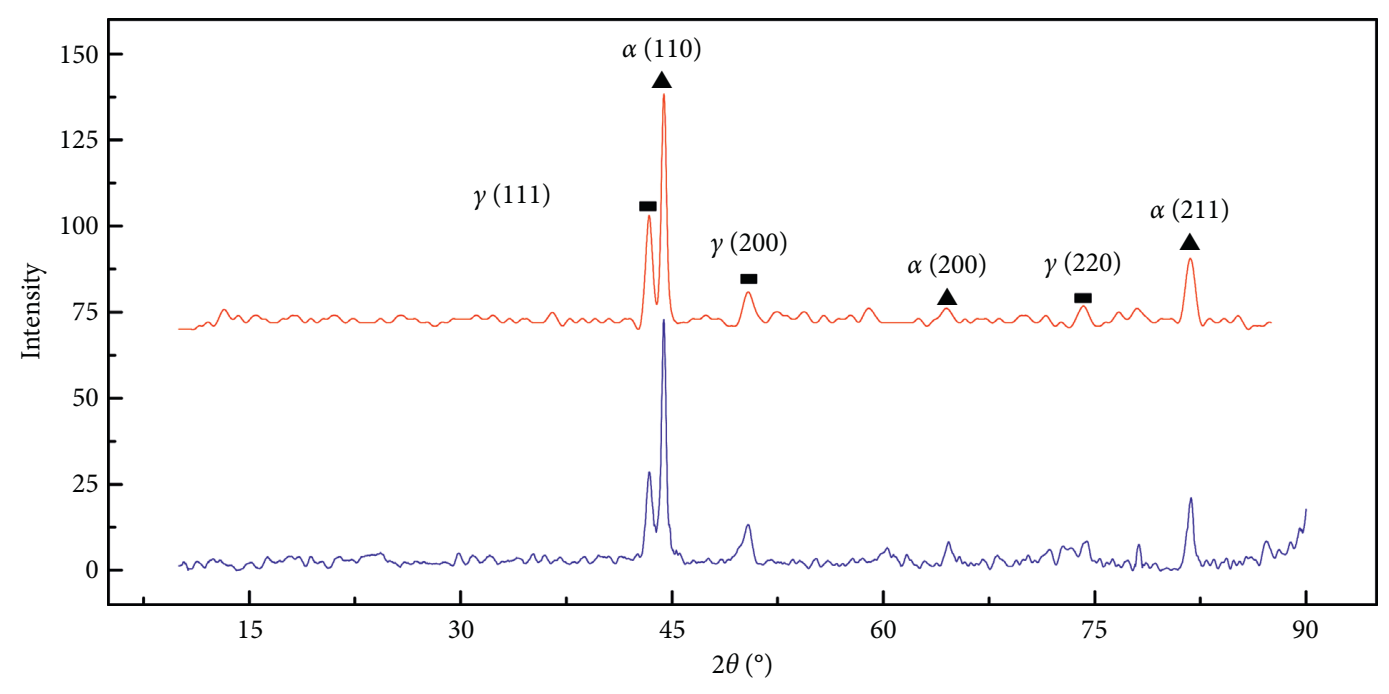

$30 \mathrm{~mm} / \mathrm{min}$

$50 \mathrm{~mm} / \mathrm{min}$

(a)

Figure 5: Continued. 


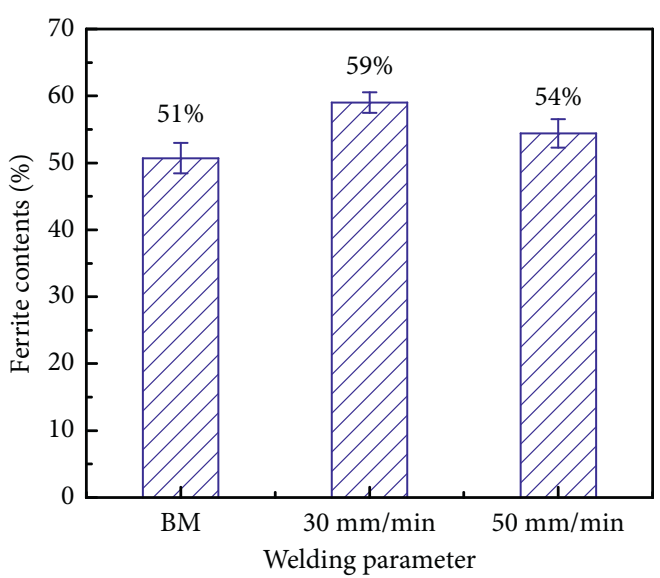

(b)

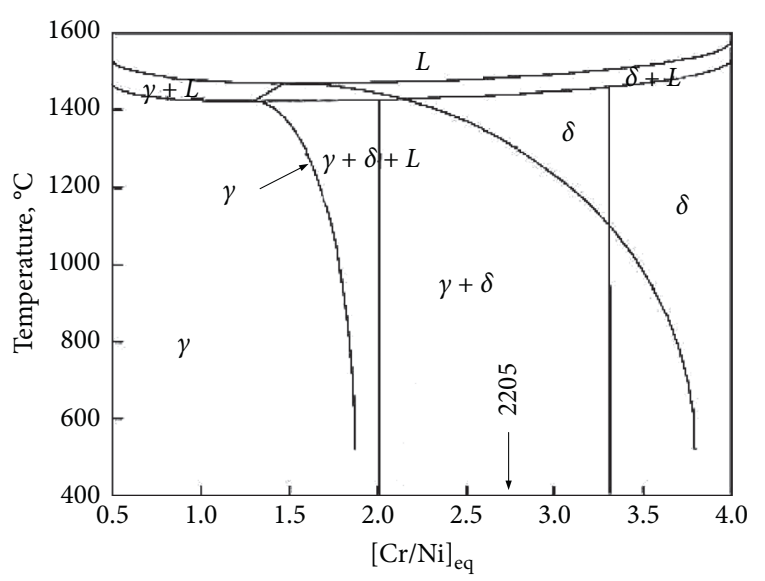

(c)

FIGURE 5: Phase composition results of the base material and stir zones at different welding speeds: (a) X-ray diffraction patterns of stir zones, (b) ferrite contents in base material and stir zones, and (c) phase diagram for 2205 DSS.

3.2. Corrosion Behavior. The open-circuit potentials (OCP) and polarization curves of the BM and SZs are illustrated in Figure 6. The electrochemical corrosion parameters, that is, OCP, corrosion potentials $\left(E_{\text {corr }}\right)$, corrosion current densities $\left(I_{\text {corr }}\right)$, pitting potentials $\left(E_{p}\right)$, Tafel slopes on anode $\left(\beta_{a}\right)$ and cathode $\left(\beta_{c}\right)$, and polarization resistances $\left(R_{p}\right)$, are summarized in Table 2. As shown in Figure 5(a), all the polarization curves appear to be similar in shape and consist of a wide passive region with a small active-passive transition region. This indicates that all the specimens experience passivating and pitting processes. It should be noted that the tendencies of the open-circuit potentials and the corrosion potentials of the specimens are different. This can be attributed to the fact that the surfaces of the specimens have been changed by the OCP measuring process. In this study, the electrochemical corrosion parameters obtained from the polarization curves are applied for evaluating the corrosion resistances of the specimens. The SZ-30 has the lowest corrosion potential and polarization resistances and the highest corrosion current density. That is to say, the corrosion resistance of the SZ-30 is lower. In addition, the corrosion current densities, pitting potentials, and the polarization resistances of the $\mathrm{BM}$ and the $\mathrm{SZ}-50$ are almost the same. Meanwhile the corrosion potential of the SZ-50 is $12 \%$ higher than that of BM. It can be concluded that the corrosion resistance of the $\mathrm{SZ}-50$ is a little higher than that of the BM. This result is different from the result found by Sarlak et al. [12]. In their study, they pointed that the FSW process can effectively enhance the corrosion resistance of the lean duplex stainless steel. Since the corrosion resistance of the joint is dependent on its microstructure characteristics, the relationship between the corrosion resistance and the microstructure will be discussed in detail later.

Figure 7 presents EIS results for BM and SZs at different welding speeds in $3.5 \mathrm{wt} \% \mathrm{NaCl}$ solution at open circuit potential. The Nyquist plots for different specimens are shown in Figure 7(a). The EIS curves of the BM and SZs present a similar tendency and only one connected imperfect semicircle can be observed for all the specimens. It can be concluded that the semicircles are capacitive impedance arc, since all the curves are in the first quadrant of the figure. It is well known that the passivation behavior is better when the radius of the semicircle is larger $[25,26]$. Therefore, the SZ50 has highest corrosion resistance, and it is followed by the $\mathrm{BM}$ and SZ-30. This is consistent with the result of potentiodynamic polarization tests.

In order to analyze the EIS curves, an equivalent circuit compatible with the Nyquist plot is simulated, as shown in Figure 7(b). According to the fitting result, the theoretical transfer function $Z(\omega)$ can be represented by a parallel combination of a resistance $R_{c t}$ and a capacitance $C_{d l}$, and both of them are in series with another resistance $R_{s}$ :

$$
Z=R_{S}+\frac{1}{\left(1 / R_{c t}\right)+j \omega C_{d l}},
$$

where $\omega(\mathrm{rad} / \mathrm{s})$ is the frequency, $R_{s}$ is the solution resistance, and $R_{c t}$ is the charge transfer resistance. In order to obtain a satisfactory impedance simulation, the capacitor $\left(C_{d l}\right)$ can be replaced with a constant phase element $\left(\mathrm{CPE}, Q_{d l}\right)$ corresponding to the double-layer capacitance [26]. This can be explained by the microscopic roughness causing an inhomogeneous distribution in the solution resistance as well as in the double-layer capacitance [27]. $Q_{d l}$ can be expressed by the following equation:

$$
Q_{d l}=R^{n-1} C_{d l}^{n}
$$

where $n$ represents effect index ranging from -1 to 1 . The $\mathrm{CPE}$ can be regarded as an ideal capacitance if $n=1$, and the $\mathrm{CPE}$ can be regarded as an ideal resistance if $n=0$.

The EIS data are fitted to this equivalent circuit and the obtained impedance parameters are summarized in Table 3. The result shows that the SZ-50 has a greatest charge transfer resistance and it is followed by the BM and the SZ-30. This also indicates that the corrosion resistance of the SZ-50 is the highest and the corrosion resistance of the SZ-30 is the lowest. 


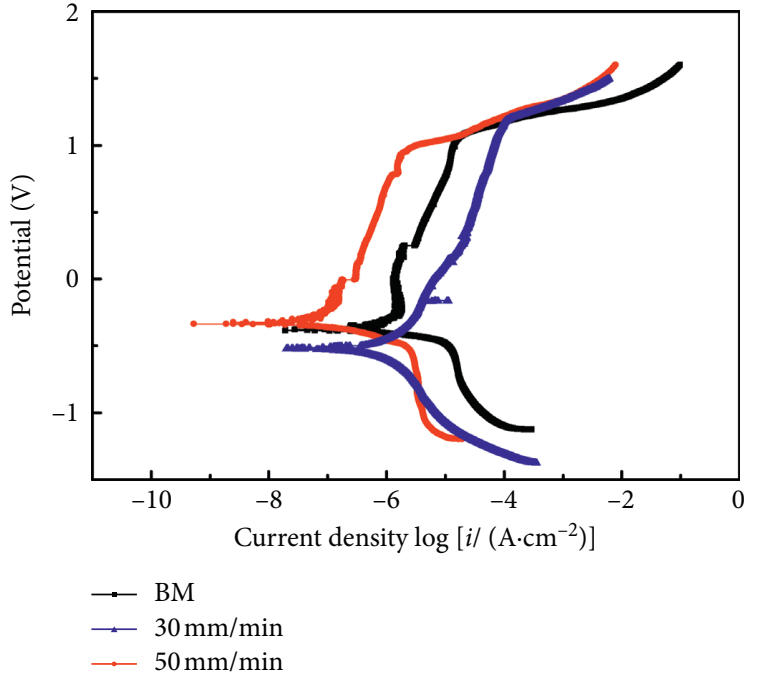

(a)

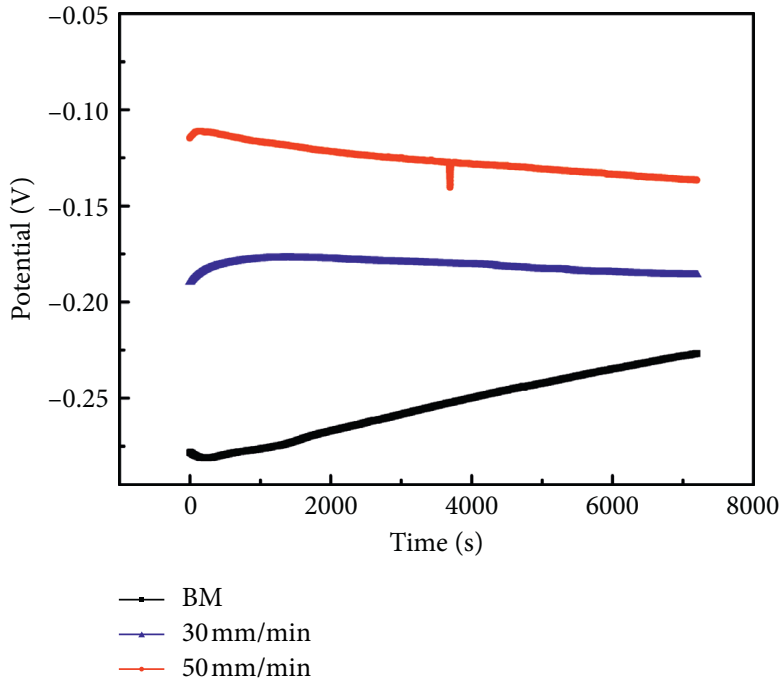

(b)

FIGURE 6: OPC and polarization curves of base material and stir zones obtained at different welding speeds: (a) OPC and (b) polarization curves.

TABLE 2: Electrochemical corrosion parameters that resulted from analysis of OPC and polarization curves for specimens.

\begin{tabular}{lccccccc}
\hline Sample & OPC $(\mathrm{V})$ & $E_{\text {corr }}(\mathrm{V})$ & $I_{\text {corr }}\left(\mathrm{A} / \mathrm{cm}^{2}\right)$ & $E_{p}(\mathrm{~V})$ & $B_{a}(\mathrm{~V})$ & $B_{c}(\mathrm{~V})$ & $R_{p}\left(\mathrm{k} \Omega \mathrm{cm}^{2}\right)$ \\
\hline $\mathrm{BM}$ & -0.23 & -0.38 & $1.62 \times 10--7$ & 1.27 & 10.2 & 137.92 & 356 \\
$30 \mathrm{~mm} / \mathrm{min}$ & -0.17 & -0.52 & $1.60 \times 10--6$ & 1.17 & 0.25 & 289.67 & 85.7 \\
$50 \mathrm{~mm} / \mathrm{min}$ & -0.14 & -0.34 & $1.66 \times 10--7$ & 1.21 & 1.07 & 113.05 & 340 \\
\hline
\end{tabular}

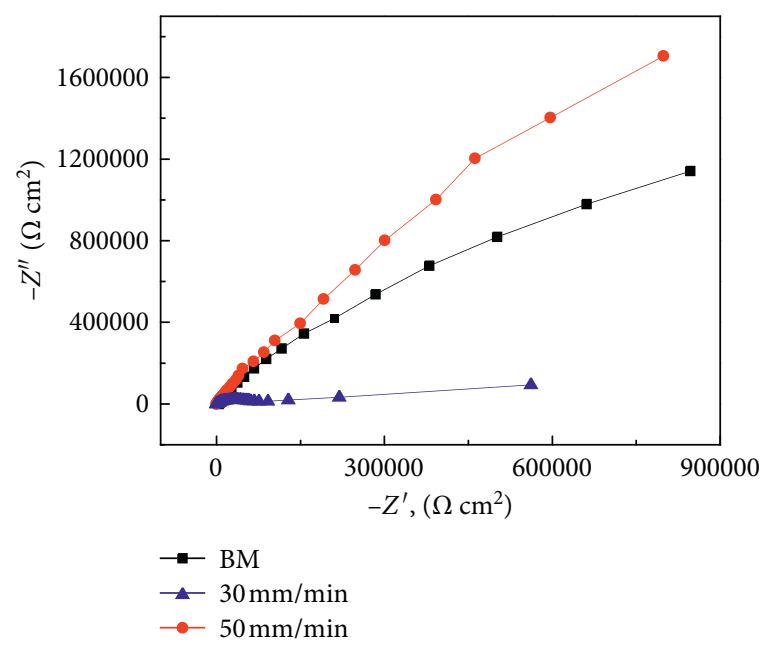

(a)

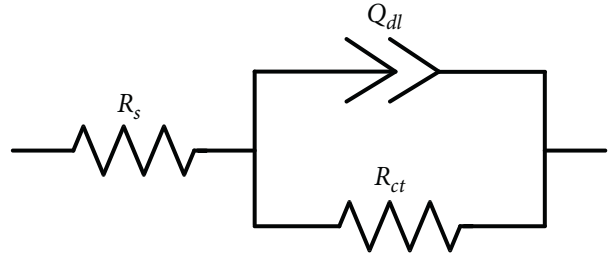

(b)

FIGURE 7: EIS results of base material and stir zones at different welding speeds: (a) Nyquist plots; (b) best equivalent circuit used to model the experimental EIS data.

TABLE 3: Electrochemical corrosion parameters that resulted from analysis of Nyquist curves for specimens.

\begin{tabular}{lccccc}
\hline Specimen & $R_{\mathrm{s}}\left(\Omega \cdot \mathrm{cm}^{2}\right)$ & $R_{\mathrm{ct}}\left(\Omega \cdot \mathrm{cm}^{2}\right)$ & $Q_{\mathrm{dl}}\left(\mu \mathrm{F} / \mathrm{cm}^{2}\right)$ & $\chi^{2}$ \\
\hline $\mathrm{BM}$ & $3.6 \times 10^{3}$ & $2.01 \times 10^{6}$ & $1.02 \times 10^{-5}$ & 0.95 & 0.01708 \\
$30 \mathrm{~mm} / \mathrm{min}$ & $0.033 \times 10^{3}$ & $0.30 \times 10^{6}$ & $1.05 \times 10^{-5}$ & 0.80 & 0.1204 \\
$50 \mathrm{~mm} / \mathrm{min}$ & $0.034 \times 10^{3}$ & $7.71 \times 10^{6}$ & $0.61 \times 10^{-5}$ & 0.86 & 0.00342 \\
\hline
\end{tabular}


Figure 8 shows the surfaces morphologies of specimens after electrochemical measurements. The corrosion pits can be observed on all the surfaces of the specimens. It can be concluded that pitting corrosion occurs after passivation in the electrochemical corrosion tests. This is consistent with the polarization curves results. In order to estimate the corrosion process, the elements contents near a typical corrosion pit were measured by EDS, as shown in Figure $8(\mathrm{~d})$, and the results are listed in Table 4 . It can be seen that the content of $\mathrm{Cr}$ is dramatically decreased in the corrosion pit, and this is the reason for pitting corrosion preferring to occur at this location. In addition, the enrichment of $\mathrm{C}$ and $\mathrm{N}$ can be also observed in corrosion pit. This may be attributed to the precipitations of $\mathrm{Cr}_{2} \mathrm{~N}$ and $\mathrm{Cr}_{23} \mathrm{C}_{6}$, which is a common phenomenon for the duplex stainless steel. Usually, the $\mathrm{Cr}$ depletion occurs near the $\mathrm{Cr}_{2} \mathrm{~N}$ and $\mathrm{Cr}_{23} \mathrm{C}_{6}$. However, due to the limited resolution ratio of EDS, it is difficult of distinguish the phases of $\mathrm{Cr}_{2} \mathrm{~N}$ and $\mathrm{Cr}_{23} \mathrm{C}_{6}$.

\subsection{The Effect of the Grain Size on the Corrosion Resistance.} It has been well demonstrated that the grain size has significant effect on the corrosion resistance of the DSS [18]. Usually, the DSS with lower grain size presents higher corrosion property because of favoring $\mathrm{Cr}$ enrichment in the passive film [18, 28]. Sarlak et al. [12] attributed the $\mathrm{Cr}$ enrichment to higher density of diffusion paths in the fine grain structure. Meanwhile Moura et al. [29] pointed out that the selective dissolution of $\mathrm{Fe}$ and formation of $\mathrm{Cr}$ oxide layer led to the $\mathrm{Cr}$ enrichment in the passive film, and the high fraction of grain boundaries accelerated the above process. In this study, the grain size of the SZ-50 is the lowest; accordingly, its corrosion resistance is the best. It should be noted that although the grain size of the SZ-30 is lower than that of BM, the SZ-30 does not present better corrosion resistance compared with the BM. It can be concluded that there are some other factors that have effects on the corrosion resistance of the DSS.

\subsection{The Effect of the Phases Compositions on the Corrosion} Resistance. The corrosion resistances for the ferrite and the austenite are different; as a result, the phases compositions should have effect on the corrosion resistance of the DSS [12]. It has been well accepted that pitting resistance number (PREN) can be applied to evaluate the corrosion resistance of the phase. For the PREN, the effects of three most important elements $\mathrm{Cr}, \mathrm{Mo}$, and $\mathrm{N}$ on pitting are taken into consideration and the PREN can be calculated according to the following equation:

$$
\mathrm{PREN}=\% \mathrm{Cr}+3.3 \% \mathrm{Mo}+20 \% \mathrm{~N} .
$$

The phase with higher PREN exhibits better pitting corrosion resistance. The relative data examined by EDS for ferrite and austenite at room temperature are listed in $\mathrm{Ta}$ ble 2 . It can be concluded that the corrosion resistance of austenite is higher than that of ferrite at room temperature, and this is consistent with the results obtained by the previous studies. That is to say, the specimen with higher austenite content should exhibit better corrosion resistance. For the BM, the relatively high austenite content can improve its corrosion resistance; as a result, the corrosion resistance is higher than that of the SZ-30. However, due to the effect of the grain size on the corrosion resistance of DSS, the corrosion resistance of BM is still lower than that of the SZ-50 (Table 5).

3.5. The Effect of the Grain Boundary Structure on the Corrosion Resistance. The grain boundaries structure is another factor that can affect the corrosion resistance of the DSS $[18,30]$. Bennett and Pickering [31] pointed out that sensitization occurred more readily and extensively in stainless steels for grain boundary structures exhibiting a low coincidence of atomic sites, corresponding to a high energy. It is well accepted that sensitization can lead to chromium-depletion near the grain boundaries and therefore the sensitization can decrease the corrosion resistance of the material [28]. In addition, the authors pointed out that, for both ferrite and austenite stainless steels, there were threshold misorientation angles of the grain boundaries, $\theta_{t}$, below which sensitization did not occur for a given aging condition. $\theta_{t}$ was equal to $7^{\circ}$ and $14^{\circ}$ for the ferrite and austenite stainless steels, respectively. Only if $\theta$ was bigger than $\theta_{t}$ could the sensitization occur and it was largely independent of the misorientation angle.

In order to quantify the effect of the grain boundary structure on the corrosion resistance for different specimens, the fractions of the grain boundaries whose misorientation angles are below the threshold misorientation angles $\left(f_{\mathrm{B}}\right)$ are calculated. In addition, the contents of the ferrite and austenite phases are taken into consideration. High $f_{\mathrm{B}}$ value indicates that the occurrence of sensitization is hard, and this is beneficial for the corrosion resistance of the DSS. In this study, $f_{\mathrm{B}}$ is calculated by the following equation:

$$
f_{\mathrm{B}}=C_{\mathrm{F}} f_{\mathrm{BF}}+C_{\mathrm{A}} f_{\mathrm{BA}} \text {, }
$$

where $C_{\mathrm{F}}$ and $C_{\mathrm{A}}$ are the contents of the ferrite and austenite phases, respectively, and $f_{\mathrm{BF}}$ and $f_{\mathrm{BA}}$ are the fractions of the grain boundaries whose misorientation angles are lower than $\theta_{t}$ for ferrite and austenite phases, respectively. The values of $C_{\mathrm{F}}, C_{\mathrm{A}}, f_{\mathrm{BF}}$, and $f_{\mathrm{BA}}$ for BM, FSW-30, and FSW-50 can be obtained from this study and they are listed in Table 6. According to equation (5), $f_{\mathrm{B}}$ for BM, SZ-30, and SZ-50 are $34.5 \%, 74.1 \%$, and $26.6 \%$, respectively. It can be concluded that the grain boundary structure of SZ-30 is the most beneficial for the corrosion resistance and it is followed by the BM and the SZ-50. However, the corrosion resistance of the SZ-30 is still the worst. That is to say, the effect of the grain boundary structure on the corrosion resistance of the DSS is the least compared to those of grain size and phase composition. 

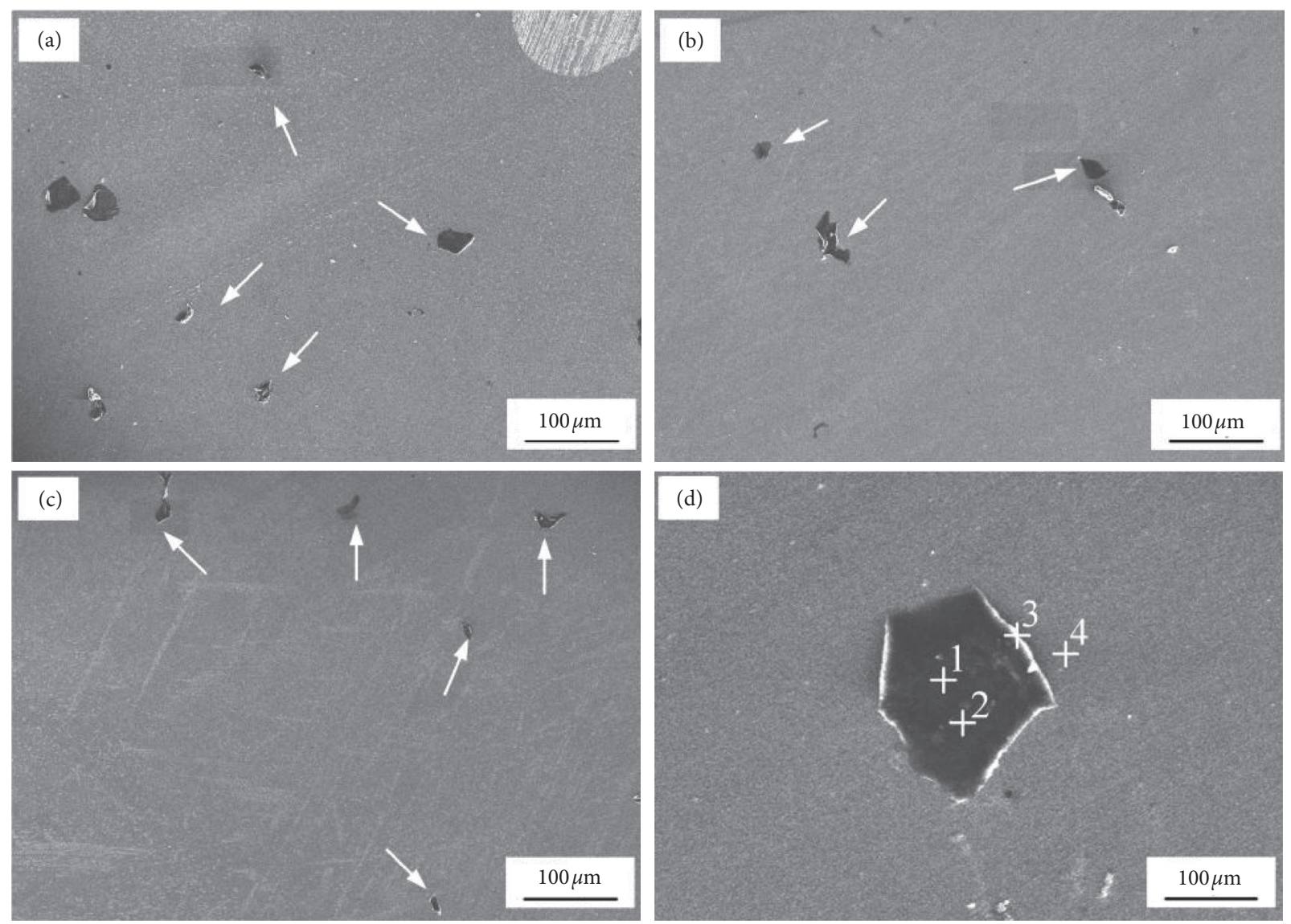

FIGURE 8: Surface morphology of specimens and EDS measuring locations near the corrosion pit after electrochemical corrosion tests: (a) base material, (b) stir zone obtained at $30 \mathrm{~mm} / \mathrm{min}$, (c) stir zone obtained at $50 \mathrm{~mm} / \mathrm{min}$, and (d) EDS measuring locations.

TABLE 4: Elements contents at different locations in Figure 8(d) measured by EDS.

\begin{tabular}{cccccccccccc}
\hline & $\mathrm{C}$ & $\mathrm{N}$ & $\mathrm{O}$ & $\mathrm{Na}$ & $\mathrm{Si}$ & $\mathrm{Cl}$ & $\mathrm{Cr}$ & $\mathrm{Mn}$ & $\mathrm{Fe}$ & $\mathrm{Ni}$ & $\mathrm{Mo}$ \\
\hline 1 & 27.54 & 7.67 & 13.83 & 1.05 & 0.60 & 1.04 & 9.28 & 0.00 & 32.07 & 3.14 & 3.72 \\
2 & 34.71 & 14.39 & 23.34 & 2.31 & 0.57 & 2.71 & 1.27 & 0.27 & 14.92 & 1.98 & 3.03 \\
3 & 5.07 & 1.26 & 1.60 & 0.08 & 0.50 & 0.00 & 16.72 & 2.12 & 63.28 & 7.70 & 1.63 \\
4 & 4.26 & 0.99 & 1.62 & 0.00 & 0.47 & 0.02 & 22.00 & 0.72 & 62.15 & 4.22 & 3.52 \\
\hline
\end{tabular}

TABLE 5: Contents distributions of main elements and PREN values in austenite and ferrite phases in stir zone.

\begin{tabular}{lcccc}
\hline Phase & Cr (\%) & Mo (\%) & N (\%) & \\
\hline Ferrite & 15.62 & 3.09 & 0.05 & 26.8 \\
Austenite & 19.53 & 2.31 & 0.42 & 35.3 \\
\hline
\end{tabular}

TABLE 6: Parameters for calculating $f_{\mathrm{B}}$ for different specimens.

\begin{tabular}{|c|c|c|c|c|c|c|}
\hline \multirow{2}{*}{$\begin{array}{l}\text { Specimen } \\
\text { Phase }\end{array}$} & \multicolumn{2}{|c|}{$\mathrm{BM}$} & \multicolumn{2}{|c|}{ SZ-30 } & \multicolumn{2}{|c|}{ SZ-50 } \\
\hline & Ferrite & Austenite & Ferrite & Austenite & Ferrite & Austenite \\
\hline$f_{\mathrm{BF}}$ or $f_{\mathrm{BA}}$ & $33.6 \%$ & $35.5 \%$ & $61.4 \%$ & $92.4 \%$ & $15.3 \%$ & $40.1 \%$ \\
\hline$C_{\mathrm{F}}$ or $C_{\mathrm{A}}$ & $50.7 \%$ & $49.3 \%$ & $59 \%$ & $41.0 \%$ & $54.4 \%$ & $45.6 \%$ \\
\hline$\underline{f_{\mathrm{B}}}$ & \multicolumn{2}{|c|}{$34.5 \%$} & \multicolumn{2}{|c|}{$74.1 \%$} & \multicolumn{2}{|c|}{$26.6 \%$} \\
\hline
\end{tabular}




\section{Conclusions}

The microstructures and corrosion resistance of 2205 DSS FSW joint were studied. The main conclusions are summarized as follows:

(1) The FSW process can refine the grains in the SZ of the joint as a result of dynamic recrystallization. This phenomenon is more obvious at welding speed of $50 \mathrm{~mm} / \mathrm{min}$ than $30 \mathrm{~mm} / \mathrm{min}$.

(2) At lower welding speed of $30 \mathrm{~mm} / \mathrm{min}$, more dislocations are induced in the SZ and the fraction of the LABs is increased obviously. With the welding speed increasing to $50 \mathrm{~mm} / \mathrm{min}$, the fraction of the LABs is decreased. Compared with austenite, the fraction of the LABs of ferrite in the SZ is increased more significantly by friction stir welding.

(3) FSW can effectively restrain the increase of ferrite content in the stirring zone. Compared with the ferrite content of $51 \%$ of the BM, the ferrite content in the SZ increases by $3 \%$ and $8 \%$, respectively, when the welding speeds are 30 and $50 \mathrm{~mm} / \mathrm{min}$.

(4) The SZ obtained at $50 \mathrm{~mm} / \mathrm{min}$ has the highest corrosion resistance, and it is followed by the BM and the $\mathrm{SZ}$ obtained at $30 \mathrm{~mm} / \mathrm{min}$. In this study, the effect of grain size on the corrosion resistance was the most significant and it was followed by the phase composition and grain boundary misorientation angle.

\section{Data Availability}

The data required to reproduce these findings cannot be shared at this time as the data also form part of an ongoing study.

\section{Conflicts of Interest}

The authors declare that they have no conflicts of interest.

\section{Acknowledgments}

The authors are grateful to be supported by the National Key Research and Development Program of China (2018YFB1306404), Science and Technology Plan Project of Guangzhou City (201704030038 and 201807010068), GDAS' Talent Introduction Project (2016GDASRC-0203), and International Science and Technology Cooperation Project of Guangzhou Economic and Technological Development Zone (2019GH15).

\section{References}

[1] M. Atapour, H. Sarlak, and M. Esmailzadeh, "Pitting corrosion susceptibility of friction stir welded lean duplex stainless steel joints," The International Journal of Advanced Manufacturing Technology, vol. 83, no. 5-8, pp. 721-728, 2015.

[2] D. G. Mohan, S. Gopi, and V. Rajasekar, "Effect of induction heated friction stir welding on corrosive behaviour, mechanical properties and microstructure of AISI 410 stainless steel," Indian Journal Of Engineering And Materials Sciences, vol. 25, no. 3, pp. 203-208, 2018.

[3] J. F. dos Santos, P. Staron, T. Fischer et al., "Understanding precipitate evolution during friction stir welding of Al-Zn$\mathrm{Mg}-\mathrm{Cu}$ alloy through in-situ measurement coupled with simulation," Acta Materialia, vol. 148, pp. 163-172, 2018.

[4] F. C. Liu, Y. Hovanski, M. P. Miles, C. D. Sorensen, and T. W. Nelson, "A review of friction stir welding of steels: tool, material flow, microstructure, and properties," Journal of Materials Science \& Technology, vol. 34, no. 1, pp. 39-57, 2018.

[5] D. G. Mohan, S. Gopi, and V. Rajasekar, "Mechanical and corrosion-resistant properties of hybrid-welded stainless steel," Materials Performance, vol. 57, no. 1, pp. 53-56, 2018.

[6] W. Wang, Y. Hu, T. Wu, D. Zhao, and H. Zhao, "Effect of rotation speed on microstructure and mechanical properties of friction-stir-welded 2205 duplex stainless steel," Advances in Materials Science and Engineering, vol. 2020, Article ID 5176536, 13 pages, 2020.

[7] H. M. Abubaker, N. Merah, F. A. Al-Badour, J. Albinmousa, and A. A. Sorour, "Influence of friction stir processing on mechanical behavior of 2507 SDSS," Metals, vol. 10, no. 3, p. $369,2020$.

[8] S. Emami, T. Saeid, and R. A. Khosroshahi, "Microstructural evolution of friction stir welded SAF 2205 duplex stainless steel," Journal of Alloys and Compounds, vol. 739, pp. 678689, 2018.

[9] T. Saeid, A. Abdollah-zadeh, T. Shibayanagi, K. Ikeuchi, and H. Assadi, "On the formation of grain structure during friction stir welding of duplex stainless steel," Materials Science and Engineering: A, vol. 527, no. 24-25, pp. 6484-6488, 2010.

[10] T. Saeid, A. Abdollah-zadeh, H. Assadi, and F. Malek Ghaini, "Effect of friction stir welding speed on the microstructure and mechanical properties of a duplex stainless steel," $M a$ terials Science and Engineering: A, vol. 496, no. 1-2, pp. 262-268, 2008.

[11] I. Sugimoto, S. H. C. Park, S. Hirano, H. Saito, and S. Hata, "Microscopic observation of precipitation behavior at friction stirring zone of super duplex stainless steel," Materials Transactions, vol. 60, no. 9, pp. 2003-2007, 2019.

[12] H. Sarlak, M. Atapour, and M. Esmailzadeh, "Corrosion behavior of friction stir welded lean duplex stainless steel," Materials \& Design, vol. 66, pp. 209-216, 2015.

[13] J. Li, X. Liu, G. Li, P. Han, and W. Liang, "Characterization of the microstructure, mechanical properties, and corrosion resistance of a friction-stir-welded joint of hyper duplex stainless steel," Metals, vol. 7, no. 4, p. 138, 2017.

[14] H.-H. Cho, H. N. Han, S.-T. Hong et al., "Microstructural analysis of friction stir welded ferritic stainless steel," Materials Science and Engineering: A, vol. 528, no. 6, pp. 28892894, 2011.

[15] S. H. C. Park, Y. S. Sato, H. Kokawa, K. Okamoto, S. Hirano, and M. Inagaki, "Microstructural characterisation of stir zone containing residual ferrite in friction stir welded 304 austenitic stainless steel," Science and Technology of Welding and Joining, vol. 10, no. 5, pp. 550-556, 2013.

[16] F. J. Humphreys and M. Hatherly, Recrystallization and Related Annealing Phenomena, Pergamon Press, New York, NY, USA, 1995.

[17] Y. S. Sato, T. W. Nelson, and C. J. Sterling, "Recrystallization in type $304 \mathrm{~L}$ stainless steel during friction stirring," Acta Materialia, vol. 53, no. 3, pp. 637-645, 2005. 
[18] K. D. Ralston and N. Birbilis, "Effect of grain size on corrosion: a review," Corrosion, vol. 66, no. 7, pp. 075005-075013, 2010.

[19] R. Merello, F. J. Botana, J. Botella, M. V. Matres, and M. Marcos, "Influence of chemical composition on the pitting corrosion resistance of non-standard low-Ni high-Mn-N duplex stainless steels," Corrosion Science, vol. 45, no. 5, pp. 909-921, 2003.

[20] R. Badji, M. Bouabdallah, B. Bacroix, C. Kahloun, K. Bettahar, and N. Kherrouba, "Effect of solution treatment temperature on the precipitation kinetic of $\sigma$-phase in 2205 duplex stainless steel welds," Materials Science and Engineering: A, vol. 496, no. 1-2, pp. 447-454, 2008.

[21] M. Pohl, O. Storz, and T. Glogowski, "Effect of intermetallic precipitations on the properties of duplex stainless steel," Materials Characterization, vol. 58, no. 1, pp. 65-71, 2007.

[22] G. Çam and S. Mistikoglu, "Recent developments in friction stir welding of Al-alloys," Journal of Materials Engineering and Performance, vol. 23, no. 6, pp. 1936-1953, 2014.

[23] R. S. Mishra and Z. Y. Ma, "Friction stir welding and processing," Materials Science and Engineering R, vol. 50, no. 1-2, pp. 1-78, 2005.

[24] T. F. A. Santos, H. S. Idagawa, and A. J. Ramirez, “Thermal history in UNS S32205 duplex stainless steel friction stir welds," Science and Technology of Welding and Joining, vol. 19, no. 2, pp. 150-156, 2013.

[25] D. Cai, S. Han, S. Zheng, Z. Luo, Y. Zhang, and K. Wang, "Microstructure and corrosion resistance of Al5083 alloy hybrid plasma-MIG welds," Journal of Materials Processing Technology, vol. 255, pp. 530-535, 2018.

[26] A. Moteshakker and I. Danaee, "Microstructure and corrosion resistance of dissimilar weld-joints between duplex stainless steel 2205 and austenitic stainless steel 316L," Journal of Materials Science \& Technology, vol. 32, no. 3, pp. 282-290, 2016.

[27] H. Jafari, I. Danaee, H. Eskandari, and M. RashvandAvei, "Electrochemical and theoretical studies of adsorption and corrosion inhibition of $\mathrm{N}, \mathrm{N}^{\prime}$-Bis(2-hydroxyethoxyacetophenone)2,2-dimethyl-1,2-propanediimine on low carbon steel (API 5L grade B) in acidic solution," Industrial \& Engineering Chemistry Research, vol. 52, no. 20, pp. 6617-6632, 2013.

[28] A. Lü, Y. Zhang, Y. Li, G. Liu, Q. Zang, and C. Liu, "Effect of nanocrystalline and twin boundaries on corrosion behavior of 3161 stainless steel using SMAT," Acta Metallurgica Sinica (English Letters), vol. 19, no. 3, pp. 183-189, 2006.

[29] V. S. Moura, L. D. Lima, J. M. Pardal, A. Y. Kina, R. R. A. Corte, and S. S. M. Tavares, "Influence of microstructure on the corrosion resistance of the duplex stainless steel UNS S31803," Materials Characterization, vol. 59, no. 8, pp. 1127-1132, 2008.

[30] I. Roy, H. Yang, L. Dinh, I. Lund, J. Earthman, and F. Mohamed, "Possible origin of superior corrosion resistance for electrodeposited nanocrystalline Ni," Scripta Materialia, vol. 59, no. 3, pp. 305-308, 2008.

[31] B. W. Bennett and H. W. Pickering, "Effect of grain boundary structure on sensitization and corrosion of stainless steel," Metallurgical Transactions A, vol. 18, no. 6, pp. 1117-1124, 1991. 